\title{
Resistivity Fractal Dimension for Characterizing Shajara Reservoirs of the Permo-Carboniferous Shajara Formation Saudi Arabia
}

\author{
Khalid Elyas Mohamed Elameen Alkhidir* \\ Department of Petroleum and Natural Gas Engineering, King Saud University, Saudi Arabia
}

Submission: May 07, 2018; Published: May 18, 2018

*Corresponding author: Khalid Elyas Mohamed Elameen Alkhidir, Department of Petroleum and Natural Gas Engineering, College of Engineering, King Saud University, Saudi Arabia, Email: kalkhidir@ksu.edu.sa

\begin{abstract}
Sandstone samples were collected from the surface type section of the Permo-Carboniferous Shajara Formation for detailed reservoir characterization. Capillary pressure experiment was performed to contact porosity and permeability was derived from the Data. Resistivity was calculated from the distribution of pores and the fractal dimension was proven from the relationship between water saturation and resistivity. In addition to field observation and obtained results of fractal dimension, the Shajara reservoirs of the permo-Carboniferous Shajara Formation were divided here into three fractal dimension units. The units from bottom to top are: Lower Shajara Resistivity Fractal dimension Unit, Middle Shajara Resistivity Fractal Dimension Unit, and Upper Shajara Resistivity Fractal Dimension Unit. These units were also proved by geometric relaxation time of induced polarization fractal dimension. It was found that the resistivity fractal dimension is similar to the geometric relaxation time of induced polarization. It was also reported that the obtained fractal dimension speeds with increasing resistivity and relaxation time due to an increase in pore connectivity.
\end{abstract}

Keywords: Shajara reservoirs; Shajara formation; Resistivity fractal dimension.

\section{Introduction}

The pore micro geometrical parameters play an important role in the physical properties of low-resistivity sandstone reservoir was investigated by Cerepi A, et al. [1]. Oil finding in low resistivity reservoir was reported by Pramudhita AB, et al. [2]. Low resistivity pay zones dislay low resistivity due to the presenece of conductive minerals such as pyrite, sulphides and graphite in the reservoir was reported by Mashaba V, et al. [3]. The features of low amplitude structure, high clay content, high irreducible water saturation, and high formation water salinity are attributed to the origin of low resistivity oil layer was described by Feng $\mathrm{C}$, et al. [4]. An increase of permeability with an increase of geometric and arithmetic relaxation time of induced polarization and increasing porosity was documented by Moasong T, et al. [5]. An increase of bubble pressure fractal dimension and pressure head fractal dimension and decreasing pore size distribution index and fitting parameters $\mathrm{m}^{*} \mathrm{n}$ due to possibility of having interconnected channels was confirmed by Alkhidir KEME [6]. An increase of fractal dimension with increasing permeability and relaxation time of induced polarization due to increase in pore connectivity was reported by Alkhidir KEME [7,8]. An increase of electric potential energy fractal dimension with increasing permeability was reported by Alkhidir KEME [9].

\section{Method and Materials}

Samples were collected from the surface type section of the Shajara reservoirs of the Permo-carboniferous shajara formation at latitude $26^{\circ} \mathrm{C} 52^{\prime} 17.4^{\prime \prime}$, longitude $43^{\circ} \mathrm{C} 36^{\prime} 18^{\prime \prime}$ Porosity was measured and permeability was derived from the measured capillary pressure data.

The resistivity can be scaled as

$$
S_{w}=\left[\frac{\Omega}{\Omega_{\max }}\right]^{[3-D f]}
$$

Where $\mathrm{S}_{\mathrm{w}}$ is the water saturation, $\Omega$ = resistivity in ohm meter.

$\Omega$ max $=$ maximum resistivity in ohm meter.

$\mathrm{Df}=$ fractal dimension

Equation 1 can be proofed from

$$
K=\left[\frac{1}{120} * \frac{1}{F^{3}} * \frac{1}{\sigma^{2}}\right]
$$

Where $\mathrm{k}=$ permeability in millidarcy (md). 
$1 / 120$ is a constant in square Siemens /square meter * mill Darcy

$\mathrm{F}=$ formation electrical resistivity factor in zero dimension

$\sigma=$ quadrature conductivity in Siemens / meter

$$
\text { But; } \frac{1}{\sigma^{2}}=\Omega^{2}
$$

Insert equation 3 into equation 2

$$
\begin{aligned}
& K=\left[\frac{1}{120} * \frac{1}{F^{3}} * \Omega^{2}\right] \\
& \text { If }\left[\frac{1}{120} * \frac{1}{F^{3}} * \Omega^{2}\right]=\frac{r^{2}}{8^{*} F}=K
\end{aligned}
$$

$r$ in equation 5 is the pore throat radius. Equation 5 after rearrange will become

$$
8 * F^{*} \Omega^{2}=\left[120 * F^{3} * r^{2}\right]
$$

Equation 6 after simplification will result in

$$
\Omega^{2}=\left[15 * F^{2} * r^{2}\right]
$$

Take the square root of both sides of Equation 7

$$
\sqrt{\Omega^{2}}=\sqrt{\left[15 * F^{2} * r^{2}\right]}
$$

Equation 8 after simplification will become

$$
\Omega=\sqrt{15 *} F * r
$$

The pore throat radius $\mathrm{r}$ can be scaled as

$$
V \alpha r^{3-D f}
$$

Where $v$ is the cumulative pore volume. Differentiate equation 10 with respect to $r$

$$
\frac{d v}{d r}=\alpha r^{2-D f}
$$

Integrate equation 11

$$
\begin{aligned}
& \int d v=\text { cons } \tan t * \int_{r \min }^{r} r^{2-D f} * d r \\
& v=\frac{\text { cons } \tan t}{3-D f} *\left[r^{3-D f}-r_{\min }^{3-D f}\right]
\end{aligned}
$$

The total pre volume can be integrated as follows:

$$
\int \text { vtotal }=\int_{r \min }^{r \max } r^{2-D f} * d r
$$

The result of total pore volume integral

$$
V_{\text {total }}=\frac{\text { cons } \tan t}{3-D f} *\left[r_{\max }^{3-D f}-r_{\min }^{3-D f}\right]
$$

Divide equation 13 by equation 15

$$
\frac{V}{V_{\text {total }}}=\frac{\left[\frac{\text { cons } \tan t}{3-D f} *\left[r^{3-D f}-r_{\min }^{3-D f}\right]\right]}{\left[\frac{\text { cons } \tan t}{3-D f} *\left[r_{\text {max }}^{3-D f}-r_{\min }^{3-D f}\right]\right]}
$$

Equation 16 after simplification will become

$$
S_{w}=\left[\frac{r}{r_{\max }}\right]^{[3-D f]}
$$

Insert equation 9 into equation 17

$$
S w=\left[\frac{\left(\frac{\Omega}{\sqrt{15} * F}\right]}{\left[\left(\frac{\Omega_{\max }}{\sqrt{15} * F}\right]\right]}\right.
$$

Equation 18 after simplification will become

$$
S w=\left[\frac{\Omega}{\Omega_{\max }}\right]^{3-D f}
$$

Equation 19 is the proof of equation 1

The geometric relaxation time of induced polarization can be scaled as

$$
S w=\left[\frac{I P T g^{1.57^{\frac{1}{2}}}}{I P T g \max ^{1.57^{\frac{1}{2}}}}\right]
$$

Where Sw = water saturation

$\mathrm{IPTg}=$ geometric relaxation time of induced polarization in milliseconds.

IPTgmax $=$ maximum geometric relaxation time of induced polarization in milliseconds.

$\mathrm{Df}=$ fractal dimension.

Equation 20 can be proofed from

$$
K=9.6 *\left(I P T g * \Phi^{4}\right)^{1.57}
$$

$\mathrm{k}=$ permeability in millidarcy

$9.6=$ constant .

$\Phi=$ porosity.

$1.57=$ constant.

The maximum permeability can be scaled as

$$
K \max =9.6 *\left(I P T g \max * \Phi^{4}\right)^{1.57}
$$

Divide equation 21 by equation 22

$$
\left[\frac{K}{K \max }\right]=\frac{\left[9.6 *\left[\operatorname{IPTg} * \Phi^{4}\right]^{1.57}\right]}{\left[9.6 *\left[I P T g \max * \Phi^{4}\right]^{1.57}\right]}
$$

Equation 23 after simplification will become

$$
\left[\frac{K}{K \max }\right]=\frac{[I P T g]^{1.57}}{[I P T g \max ]^{1.57}}
$$

Take the square root of equation 24

$$
\sqrt{\left[\frac{K}{K \max }\right]}=\sqrt{\frac{[I P T g]^{1.57}}{[I P T g \max ]^{1.57}}}
$$


Equation 25 can also be written as

$$
\left[\frac{K^{\frac{1}{2}}}{K \max ^{\frac{1}{2}}}\right]=\left[\frac{I P T g^{1.57^{\frac{1}{2}}}}{I P T g \max ^{1.57^{\frac{1}{2}}}}\right]
$$

Take the Logarithm of equation 26

$$
\begin{gathered}
\log \left[\frac{K^{\frac{1}{2}}}{K \max ^{\frac{1}{2}}}\right]=\log \left[\frac{I P T g^{1.57^{\frac{1}{2}}}}{I P T g \max ^{1.57^{\frac{1}{2}}}}\right] \\
\text { But } ; \log \left[\frac{K^{\frac{1}{2}}}{K \max ^{\frac{1}{2}}}\right]=\log \frac{S w}{[3-D f]}
\end{gathered}
$$

Insert equation 28 into equation 27

$$
\log \frac{S w}{3-D f}=\log \left[\frac{I P T g^{1.57^{\frac{1}{2}}}}{I P T g \max ^{1.57^{\frac{1}{2}}}}\right]
$$

If we remove the Log from equation 29

$$
S w=\left[\frac{I P T g^{1.57^{\frac{1}{2}}}}{I P T g \max ^{1.57^{\frac{1}{2}}}}\right]^{3-D f}
$$

Equation 30 the proof of equation 20 which relates the water saturation, the geometric relaxation time of induced polarization, the maximum geometric relaxation time of induced polarization, and the fractal dimension

\section{Results and Discussion}

Petro physical data characterizing Shajara reservoirs of the permo-Carboniferous Shajara Formation were presented in Table 1. These sandstone reservoirs were divided into three bodies, from bottom to top are: lower, middle, and upper shajara reservoir as shown in Figure 1. Concerning the lower shajara reservoir, it is domenstrated by six sandtone samples as presented in Figure 1, four of which named as SJ1, SJ2, SJ3, and SJ4 as presented in Table 1 were selected for capillary pressure measurement. Their results of resistivity and geometric relaxation time fractal dimensions were displayed in Table 1. Sample SJ1 with a porosity value of about $29 \%$ and permeability equal to 1680 millidarcy, whose resistivity and geometric relaxation time fractal dimensions was found to be 2.7859 as revealed in Table 1 . Sample SJ2 is defined by $35 \%$ porosity and permeability around 1955 millidarcy. Its resistivity and geometric relaxation time fractal dimensions of induced polarization equal 2.7748. As we progress from sample SJ2 to sample SJ3 an extreme reduction in permeability was encountered from 1955 millidarcy to 56 millidary which accounts for decrease in fractal dimension from 2.7848 to 2.4379 as explained in Table 1. Such drastic chane in permeability and fractal dimension can account for heterogeneity which is an importment parameter in reservoir qulaity assessment. Again an increase in permeability from 56 millidary to 176 millidarcy was reported as we proceed from sample SJ3 to SJ4 as delineated in Table 1. Such increase in permeability gives rise to fractal dimension from 2.4379 to 2.6843 as presented in Table 1 .

However the middle Shajara Reservoir is designated by four sandstone samples as described in Figure 1, three of which so called SJ7, SJ8, and SJ9 as shown in Table 1 were selected for capillary measurement. Their poroperm data were presented in Table 1 . Their resistivity and geometric relaxation time fractal

\begin{tabular}{|c|c|c|c|c|c|c|}
\hline Formation & Reservoirs & Samples & Porosity & Permeability & $\begin{array}{l}\text { Resistivity } \\
\text { Fractal } \\
\text { Dimension }\end{array}$ & $\begin{array}{c}\text { Geometric } \\
\text { Relaxation } \\
\text { Time Fractal } \\
\text { Dimension }\end{array}$ \\
\hline \multirow{10}{*}{$\begin{array}{c}\text { Permo- } \\
\text { Carboniferous } \\
\text { Shajara Formation }\end{array}$} & \multirow{3}{*}{$\begin{array}{c}\text { Upper Shajara } \\
\text { Reservoir }\end{array}$} & SJ13 & 25 & 973 & 2.7872 & 2.7872 \\
\hline & & SJ12 & 28 & 1440 & 2.7859 & 2.7859 \\
\hline & & SJ11 & 36 & 1197 & 2.7586 & 2.7586 \\
\hline & \multirow{3}{*}{$\begin{array}{l}\text { Middle Shajara } \\
\text { Reservoir }\end{array}$} & SJ9 & 31 & 1394 & 2.7786 & 2.7786 \\
\hline & & SJ8 & 32 & 1344 & 2.7752 & 2.7752 \\
\hline & & SJ7 & 35 & 1472 & 2.7683 & 2.7683 \\
\hline & \multirow{4}{*}{$\begin{array}{c}\text { Lower Shajara } \\
\text { Reservoir }\end{array}$} & SJ 4 & 30 & 176 & 2.6843 & 2.6843 \\
\hline & & SJ3 & 34 & 56 & 2.4379 & 2.4379 \\
\hline & & SJ2 & 35 & 1955 & 2.7748 & 2.7748 \\
\hline & & SJ1 & 29 & 1680 & 2.7859 & 2.7859 \\
\hline
\end{tabular}
dimensions were higher than samples SJ3 and SJ4 due to an increase in their permeabilities as displayed in Table 1.

Table 1: Petrophysical model showing the the thee Shajara Reservoirs of the Permo-Carboniferous shajara Formation with their corresponding values of resistivity and geometric relaxation time fractal dimensionsof induced polarization. 


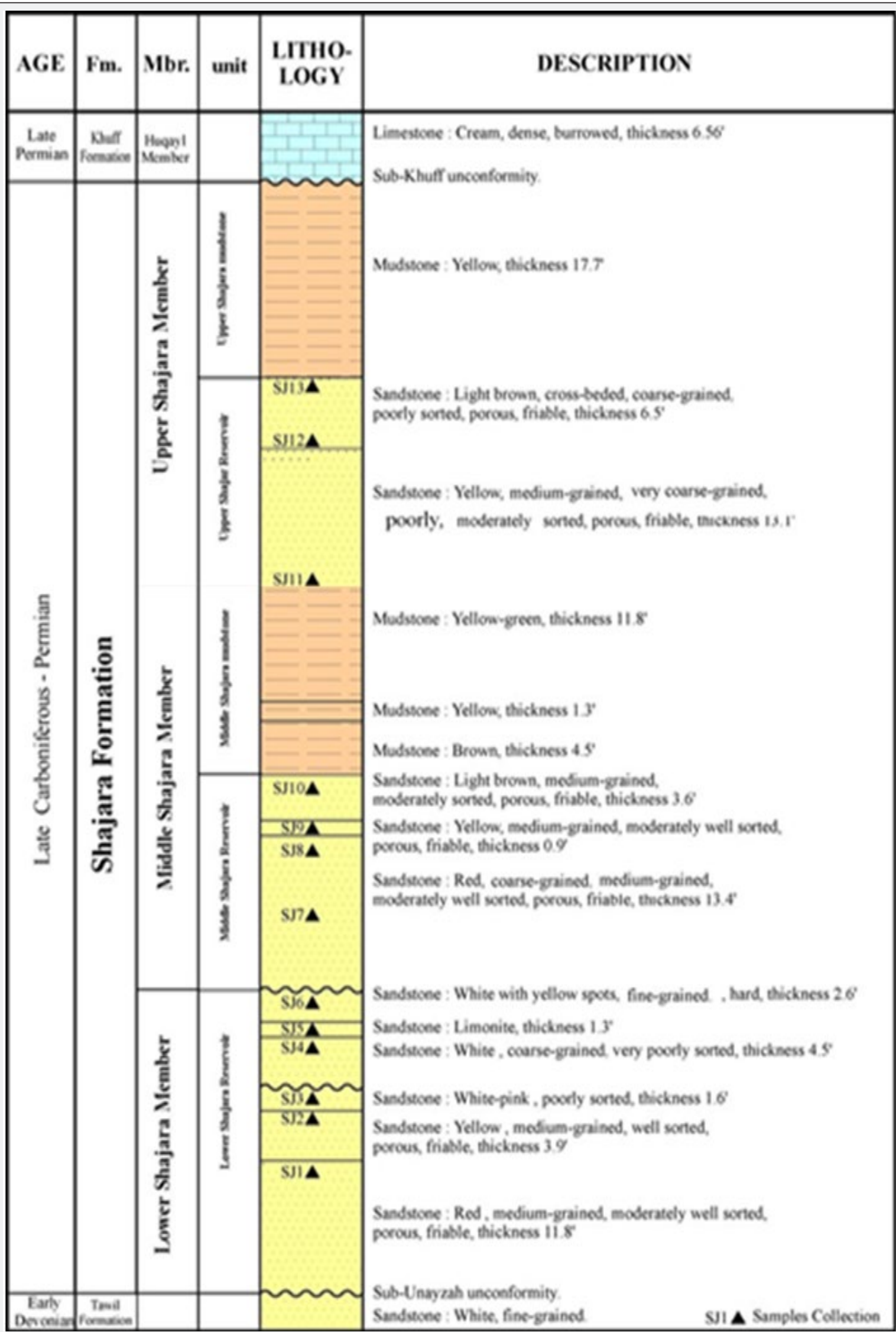

Figure 1: Stratigraphic column of the type section of the Permo-carboniferous Shajara Formation latitude $26^{\circ} \mathrm{C} 52^{\prime} 17.4^{\prime \prime}$, longitude 43 ${ }^{\circ} \mathrm{C} 36^{\prime} 18^{\prime \prime}$ 
The upper shajara reservoir is illustrated by three samples labeled as SJ11, SJ12, and SJ13 as described in Table 1. Their resistivity and geometric relaxation time fractal dimension values are also higher than samples SJ3 and SJ4 owing to an increase in their flow capacity (permeability) as demonstrated in Table 1.
Overall a plot of resistivity fractal dimensions versus geometric relaxation time fractal dimension fractal dimensions of induced polarization (Figure 2) delineates three zones of varing petrophysical characteristics. Such discrepancy in fractal dimension can account for heterogeneity which is a key parameter in reservoir quality assessment.

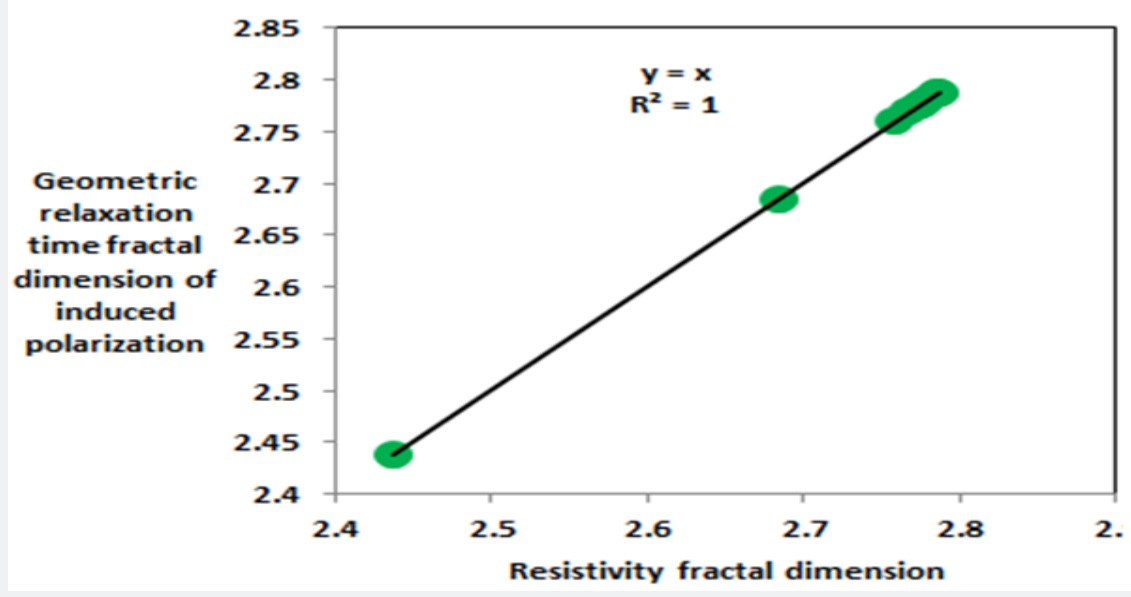

Figure 2: Resistivity fractal dimension versus geometric relaxation time fractal dimension of induced polarization.

\section{Conclusion}

The sandstones of the Shajara reservoirs of the PermoCarboniferous Shajara Formation were divided here into three bodies based on resistivity fractal dimension. Theses reservoir bodies were also confirmed by geometric relaxation time fractal dimension of induced polarization. The heterogeneity of the Shajara reservoirs increases with an increase of fractal dimension, permeability, giving rise to an increase in pore size distribution.

\section{Acknowledgement}

The author would like to thank college of Engineering, King Saud University, Department of Petroleum and Natural Gas Engineering, Department of Chemical Engineeing, Research Centre at college of Engineeing, King Abdullal Institute for Research and Consulting Studies for their supports.

\section{References}

1. Cerepi A, Durand C, Brosse E (2002) Pore micro geometry analysis in Low-resistivity sandstone reservoirs. Journal of Petroleum Science and Engineering 35(3-4): 205-232.

2. Pramudhita AB, Nagarani AY, Yusuf H, Yustiawan R (2013) Effective hydrocarbon probe and development of low resistivity potential in marginal oil field. Proceeding Indonesian Petroleum association, Thirty-Seventh Annual Convention and Exhibition.
3. Mashaba V, Altermann W (2015) Calculation of water saturation in low resistivity gas reservoir and pay-zones of the Cretaceous Grudja Formation, Onshore Mozambique Basin. Marine Petroleum Geology 67: $249-261$.

4. Feng C, Gingras M, Sun M, Wang B (2017) Logging characteristics and identification methods of low resistivity oil layer: Upper cretaceous of the Third Member Qingshankou Formatio, Daqingzijing Area, Songliao Basin, China. Geofluids, pp. 1-13.

5. Moasong T, Weinan W, Li L, Yizhong J, Deqin S (2017) Estimation of permeability of shaly sand reservoir from induced polarization time spectra. Journal of petroleum Science and Engineering 45(1-2): 1-10.

6. Alkhidir KEME (2017) Pressure head fractal dimension for characterizing Shajara Reservoirs of the Shajara Formation of the permo-carboniferous Unayzah Group, saudi Arabia. Archives of Petroleum and Environmental Biotechnology, pp. 1-7.

7. Alkhidir KEME (2018) Geometric relaxation time of induced polarization fractal dimension for characterizing Shajara Reservoirs of the Shajara Formation of the Permo-Carboniferous Unayzah Group, Saudi Arabia. Scifed Journal of Petroleum 2: 1-6.

8. Alkhidir KEME (2018) Arithmetic relaxation time of induced polarization fractal dimension for characterizing Shajara Reservoirs of the Shajara Formation 1(1): 1-8.

9. Alkhidir KEME (2018) Electric potential energy fractal dimension for characterizing Permo-Carboniferous Shajara Formation. Expert Opinion on Environmental Biology 7(2): 1-5. 
This work is licensed under Creative Commons Attribution 4.0 License

DOI: 10.19080/RAPSCI.2018.05.555660

\section{Your next submission with Juniper Publishers} will reach you the below assets

- Quality Editorial service

- Swift Peer Review

- Reprints availability

- E-prints Service

- Manuscript Podcast for convenient understanding

- Global attainment for your research

- Manuscript accessibility in different formats ( Pdf, E-pub, Full Text, Audio)

- Unceasing customer service

Track the below URL for one-step submission https://juniperpublishers.com/online-submission.php 